\title{
Glycoluril-tetrathiafulvalene molecular clips: on the influence of electronic and spatial properties for binding neutral accepting guests
}

\author{
Yoann Cotelle, Marie Hardouin-Lerouge, Stéphanie Legoupy, Olivier Alévêque, \\ Eric Levillain* and Piétrick Hudhomme*
}

\author{
Full Research Paper \\ Address: \\ Université d'Angers, Laboratoire MOLTECH-Anjou, CNRS UMR 6200, \\ 2 Boulevard Lavoisier, F-49045 Angers, France \\ Email: \\ Eric Levillain* - eric.levillain@univ-angers.fr; \\ Piétrick Hudhomme* - pietrick.hudhomme@univ-angers.fr \\ * Corresponding author \\ Keywords: \\ donor-acceptor interactions; glycoluril; molecular clips; \\ supramolecular chemistry; tetrathiafulvalene
}

\author{
Beilstein J. Org. Chem. 2015, 11, 1023-1036. \\ doi:10.3762/bjoc.11.115 \\ Received: 13 March 2015 \\ Accepted: 28 May 2015 \\ Published: 17 June 2015 \\ This article is part of the Thematic Series "Tetrathiafulvalene chemistry". \\ Guest Editor: P. J. Skabara \\ (c) 2015 Cotelle et al; licensee Beilstein-Institut. \\ License and terms: see end of document.
}

\begin{abstract}
Glycoluril-based molecular clips incorporating tetrathiafulvalene (TTF) sidewalls have been synthesized through different strategies with the aim of investigating the effect of electrochemical and spatial properties for binding neutral accepting guests. We have in particular focused our study on the spacer extension in order to tune the intramolecular TTF $\cdots$ TTF distance within the clip and, consequently, the redox behavior of the receptor. Carried out at different concentrations in solution, electrochemical and spectroelectrochemical experiments provide evidence of mixed-valence and/or $\pi$-dimer intermolecular interactions between TTF units from two closed clips. The stepwise oxidation of each molecular clip involves an electrochemical mechanism with three one-electron processes and two charge-coupled chemical reactions, a scheme which is supported by electrochemical simulations. The finetunable $\pi$-donating ability of the TTF units and the cavity size allow to control binding interaction towards a strong electron acceptor such as tetrafluorotetracyanoquinodimethane $\left(\mathrm{F}_{4}\right.$-TCNQ) or a weaker electron acceptor such as 1,3-dinitrobenzene $(m-\mathrm{DNB})$.
\end{abstract}

\section{Introduction}

Thanks to its remarkable redox properties and strong $\pi$-donating character demonstrated with the pioneering work of $\mathrm{F}$. Wudl in the early 1970s [1], tetrathiafulvalene (TTF) has become one of the most popular electroactive frameworks used in materials science [2-5]. In addition to the well-known access to molecular conductors [6,7] and TTF-acceptor assemblies [8,9], new concepts have been explored in the field of supramolecular chemistry using the TTF unit as a powerful electroactive 
building block [10]. Exploiting its peculiar electronic (two successive reversible oxidation steps giving rise to three stable redox states) characteristics, more and more sophisticated TTFbased supramolecular systems have been designed, being able to operate as machines, chemical sensors, redox-switchable ligands, molecular shuttles, molecular switches and logic gates [11]. Considering that molecular receptors prone to specifically recognize neutral molecules through donor-accceptor interactions are of particular interest [12], the unique $\pi$-donating ability and the planar geometry of the TTF building-block are suited to the construction of such receptors. Nevertheless, the incorporation of TTF as a $\pi$-donating element in molecular clips or tweezers for recognition of neutral electron acceptor guests is still relatively unexplored [13].

Molecular clips and tweezers can be defined as receptors presenting an open cavity composed of two interaction sites which are separated by a spacer [13-15]. Ideally, these systems are designed with the aim of sandwiching a molecular guest with a high degree of selectivity and control of the interactions between the guest and the sidewalls. While the nature and the flexibility of the spacer between the two sidewalls play a critical role in the recognition process, we were interested in rigidifying the molecular clips in order to favor the "lock and key" model [15]. This rigid structure offers the possibility to orient the interaction sites in a defined manner allowing an increase of the binding strength with the guest. In the last two decades, glycoluril-based molecular clips have shown that they were capable of acting as excellent receptors by exploiting the distance between the two aromatic sidewalls which is usually close to $7 \AA$. Since then, a large number of host systems based on this principle have been synthesized in order to use them for recognition of aromatic guest molecules through $\pi-\pi$ interactions $[16,17]$.

We recently described various glycoluril-based molecular clips 1-4 [18,19] (Figure 1) for which the structure varies by: i) the nature of connection between the glycoluril spacer and the TTF sidewalls, ii) the nature of the peripheral substituents on both TTF pincers. In this full research paper we propose to study how these structural parameters influence the electron donating ability of TTF pincers and the size of the cavity and how the control over the inter-TTFs distance within the molecular clip impacts the ability for sandwiching neutral acceptor guests. Those studies are supported by electrochemical analyses (including simulation), time-resolved spectroelectrochemical experiments and UV-visible titrations.

\section{Results and Discussion \\ Synthesis}

We have designed molecular clips 1-4 through three different synthetic strategies starting from diphenylglycoluril 5 (Scheme 1). The key building-block $\mathbf{5}$ is available in multigram scale by reaction of benzil with urea [20]. The first approach leading to molecular clips $\mathbf{1}$ and $\mathbf{2}$ is based on a straightforward double nucleophilic substitution leading to a seven-membered ring using 4,5-bis(bromomethyl)-2-thioxo-1,3-dithiole (6) [21].

In order to determine the optimized experimental procedure to carry out the urea N-alkylation of compound $\mathbf{5}$, we took advantage from literature of previous works realized on glycoluril for such reaction using a 2,3-bis(halogenomethyl)aryl derivative.

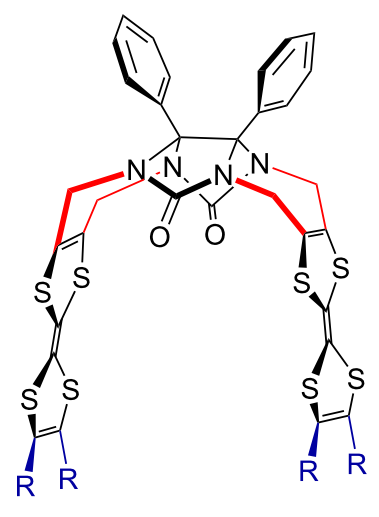

1: $\mathrm{R}=\mathrm{CO}_{2} \mathrm{CH}_{3}$

2: $\mathrm{R}=\mathrm{SCH}_{2} \mathrm{CH}_{2} \mathrm{CN}$

3: $\mathrm{R}=\mathrm{SCH}_{3}$

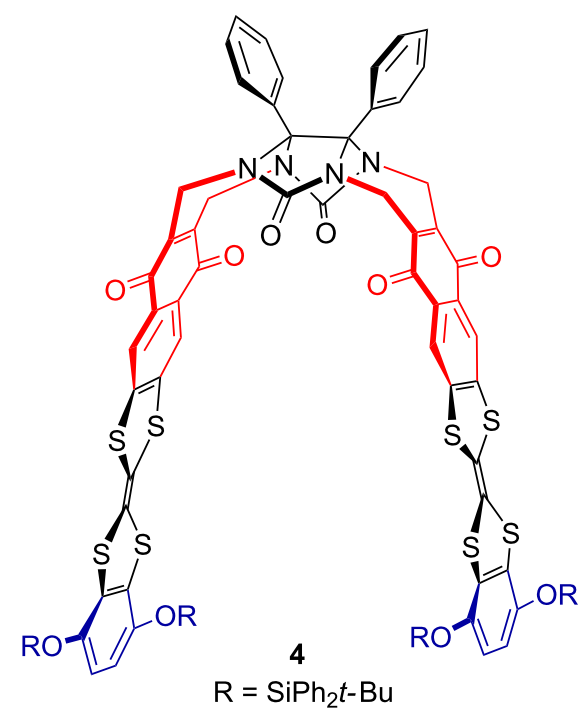

Figure 1: Structures of molecular clips 1-4. 


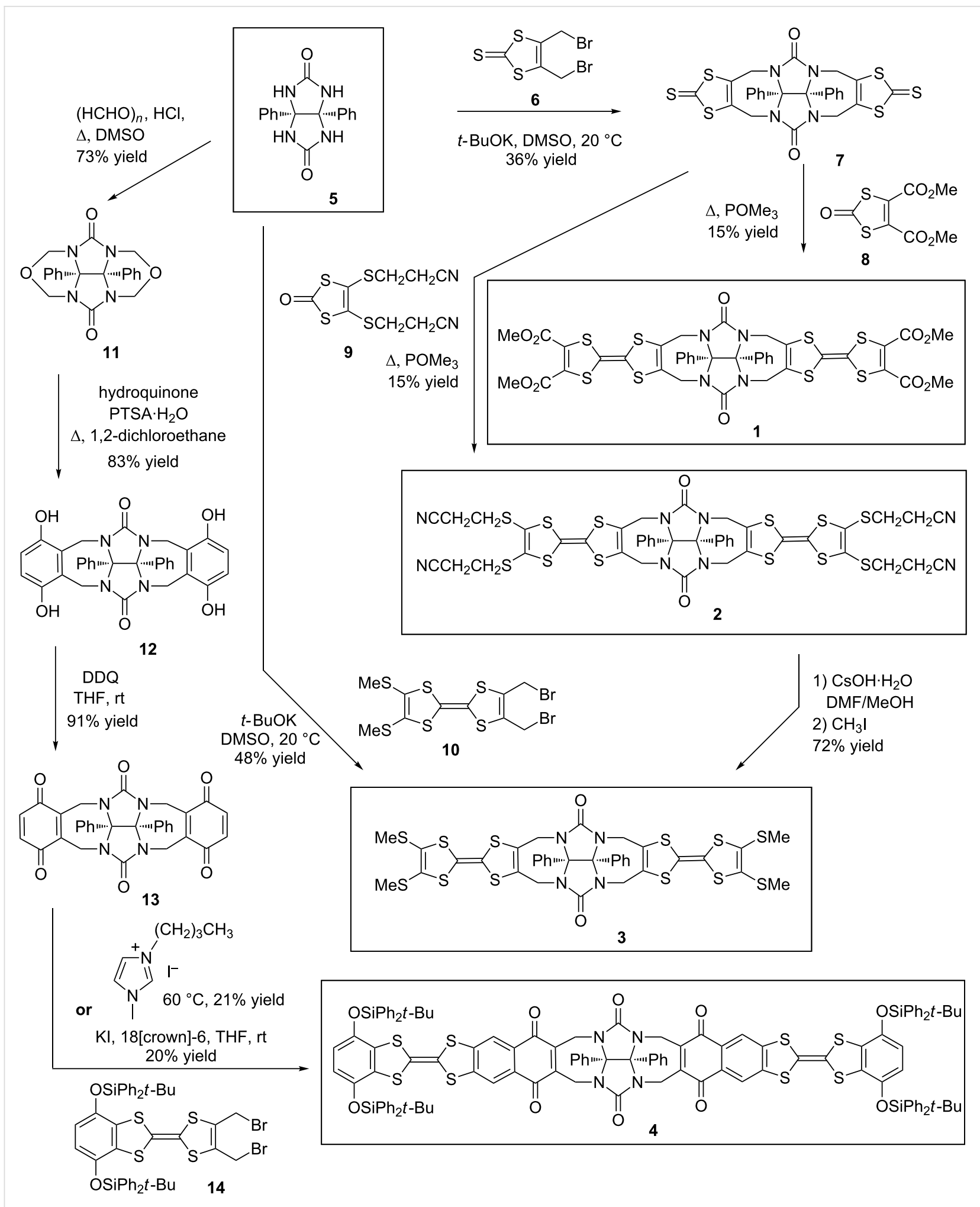

Scheme 1: Different routes developed for the synthesis of molecular clips 1-4.

Reported procedures were using $\mathrm{KOH}[22,23], t$-BuOK [24-26] between diphenylglycoluril 5 and 4,5-bis(bromomethyl)-2or $\mathrm{NaH}$ [27] as the base with DMSO as an aprotic polar solvent. thioxo-1,3-dithiole (6) as the electrophilic reagent (Scheme 2) Different experimental conditions were tested for the reaction by varying parameters such as the nature of the base, the reac- 


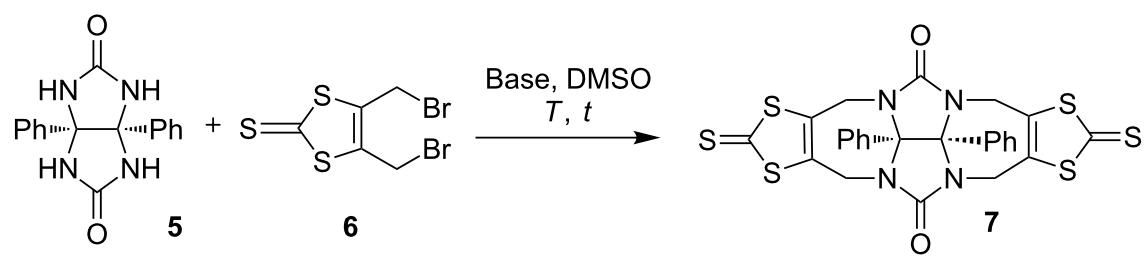

Scheme 2: Reaction between diphenylglycoluril with 4,5-bis(bromomethyl)-2-thioxo-1,3-dithiole.

tion time and the temperature (Table 1). Optimal conditions were using four equivalents of $t$-BuOK in anhydrous DMSO by keeping the temperature at $20{ }^{\circ} \mathrm{C}$ with a cryostat apparatus for $3 \mathrm{~h}$. Compound 7 was isolated in $36 \%$ yield after purification by silica gel chromatography. We should note that an increase of temperature resulted in the degradation of starting material 6.

Table 1: Optimized experimental conditions for the synthesis of com-
pound 7.
\begin{tabular}{cccc} 
Base & Temperature $(T)$ & Reaction time $(t)$ & Yield [\%] \\
\hline $\mathrm{KOH}$ & $\mathrm{rt}$ & $24 \mathrm{~h}$ & 6 \\
$\mathrm{NaH}$ & $\mathrm{rt}$ & $24 \mathrm{~h}$ & 5 \\
$\mathrm{KOH}$ & $\mathrm{rt}$ & $4 \mathrm{~h}$ & 12 \\
$t$-BuOK & $\mathrm{rt}$ & $4 \mathrm{~h}$ & 19 \\
$t$-BuOK & Controlled $30^{\circ} \mathrm{C}$ & $4 \mathrm{~h}$ & 12 \\
$t$-BuOK & Controlled $20^{\circ} \mathrm{C}$ & $3 \mathrm{~h}$ & 36 \\
\hline
\end{tabular}

This first strategy to reach clips $\mathbf{1}$ and $\mathbf{2}$ was considering the trimethylphosphite-mediated cross-coupling reaction involving 2-oxo-1,3-dithiole moiety 8 [28] as an efficient route to prepare dissymmetrical TTF derivatives [29]. The polarity of compounds which were formed was sufficiently different to allow an efficient purification by silica gel chromatography affording molecular clip 1 in $15 \%$ yield. This route was successfully applied using compound 9 [30] and clip 2 was also isolated in $15 \%$ yield. Target clip 3 was finally obtained in $72 \%$ yield by deprotection of precursor 2 using $\mathrm{CsOH} \cdot \mathrm{H}_{2} \mathrm{O}$ in $\mathrm{DMF} / \mathrm{MeOH}$ mixture [31], followed by the tetraalkylation of tetrathiolate with iodomethane. Considering that this multi-step synthesis was affording molecular clip 3 in an overall $4 \%$ yield starting from diphenylglycoluril $\mathbf{5}$, we took advantage of the accessibility of 2,3-bis(bromomethyl)TTF 10 [32] bearing methylsulfanyl groups to investigate a more straightforward strategy. Alternatively, the above methodology described for the preparation of compound 7 was efficiently applied to reach molecular clip 2 in 48\% yield using similar experimental conditions.

Whereas the synthesis of molecular clips 1, 2 and $\mathbf{3}$ uses the nucleophilic substitution onto diphenylglycoluril $\mathbf{5}$ as a key- step, the introduction of the naphthoquinone spacer in clip 4 required the previous transformation of compound $\mathbf{5}$ into a glycoluril-based framework possessing quinone moieties for developing a Diels-Alder cycloaddition strategy. Thus compound 12 [33] was prepared in 73\% yield by treatment with an excess of hydroquinone in 1,2-dichloroethane using a Friedel-Crafts alkylation as an electrophilic aromatic substitution onto compound 11 [34]. The hydroquinone moieties were subjected to a dehydrogenation reaction using DDQ in THF to reach desired glycolurildiquinone $\mathbf{1 3}$ [35] in 91\% yield. The Diels-Alder cycloaddition was carried out by treatment of bisdienophile 13 with TTF derivative 14 [36], able to give rise in situ to the transient diene by reductive elimination using naked iodide [37-39] or the iodo-ionic liquid 1-butyl-3-methylimidazolium iodide [40]. After purification by column chromatography on silica gel, we noted that complete aromatization has occurred concomitantly and molecular clip $\mathbf{4}$ was isolated in around $20 \%$ yield.

Whereas all attempts at growing crystals of molecular clips 1 and $\mathbf{4}$ of sufficient quality for X-ray analysis have been unsuccessful so far, suitable single crystals were obtained by slow diffusion from a solution of clips $\mathbf{2}$ and $\mathbf{3}$ in a $\mathrm{CH}_{2} \mathrm{Cl}_{2} /$ hexane mixture. Considering the central double bond of each TTF moiety, the intramolecular wall-to-wall distance was determined to be equal to $8.25 \AA$ and $7.41 \AA$ for clip 2 and $\mathbf{3}$, respectively (Figure 2) [18]. Then the corresponding wall-to-wall distance between the two TTF units was determined by theoretical calculations using the semi-empirical AM1 method in the case of 4 [19]. This distance was estimated to be equal to $9.7 \AA$ indicating that this enlargement around $2 \AA$ was the result mainly of the spatial contribution of the additional naphthoquinone spacer in molecular clip 4.

\section{Electrochemical properties}

The electrochemical behaviour of molecular clips 1-4 were determined using cyclic voltammetry experiments (Table 2).

These studies displayed a different electrochemical behavior for clips 1, 2 and 3 in comparison to clip 4. In the latter case, the cyclic voltammogram $(\mathrm{CV})$ showed two oxidation waves at 


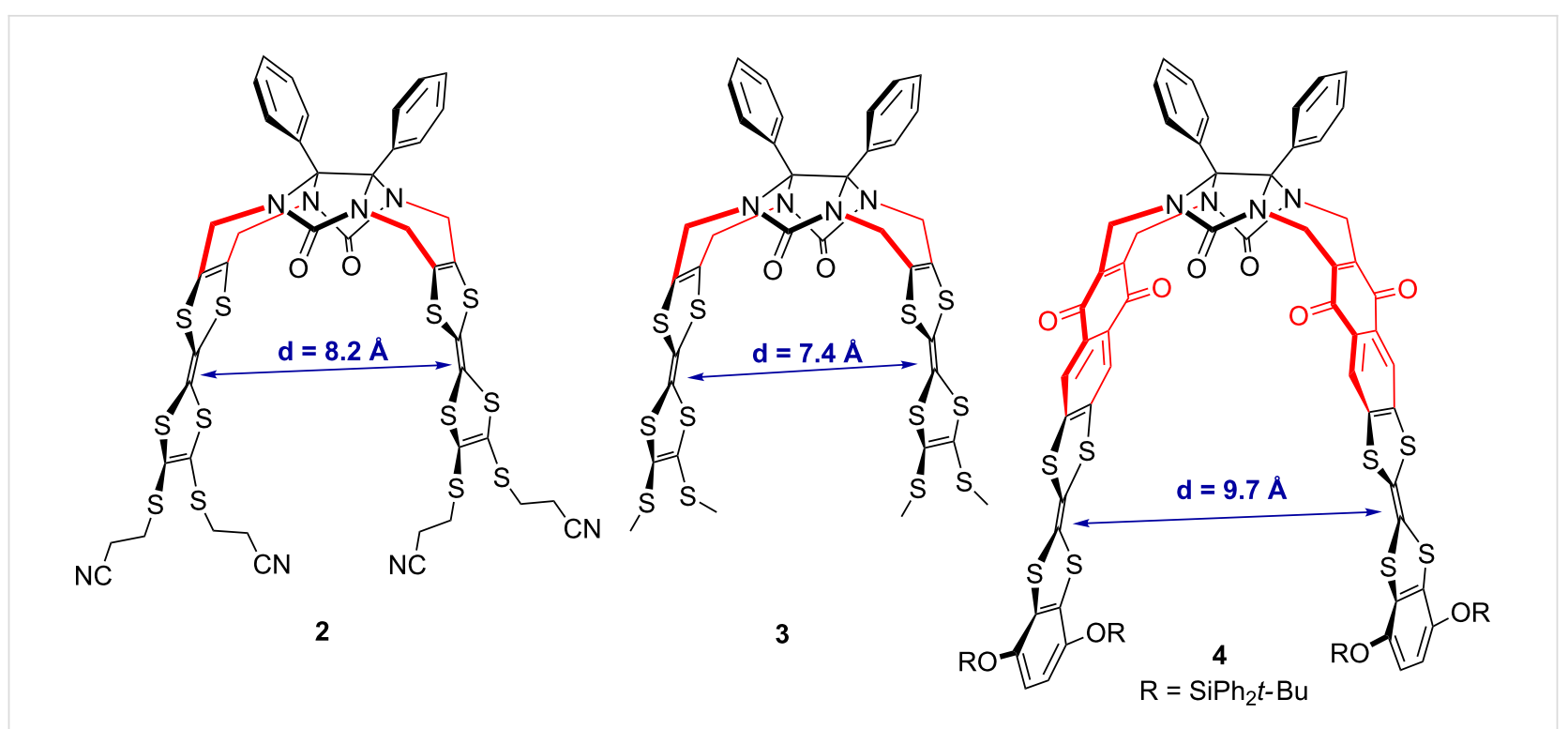

Figure 2: Intramolecular distances between TTF moieties from X-ray analysis for clips $\mathbf{2}$ and $\mathbf{3}$ and theoretical calculations for clip 4.

Table 2: Apparent redox potentials of molecular clips 1, 2, 3 and 4 reported vs $\mathrm{Fc}^{+} / \mathrm{Fc}$ in $0.1 \mathrm{M} \mathrm{TBAPF} / \mathrm{CH}_{2} \mathrm{Cl}_{2} / \mathrm{CH}_{3} \mathrm{CN} 3: 1$ on glassy carbon electrode at $100 \mathrm{mV} \cdot \mathrm{s}^{-1}$. Absolute errors on potentials were found to be around $+/-10 \mathrm{mV}$.

\begin{tabular}{ccccc} 
Clip & $E_{\mathrm{app}{ }^{0} \text { red1 }}$ & $E_{\mathrm{app} 0 \times 1}{ }^{0}$ & $E_{\mathrm{app}{ }^{0} \mathrm{ox} 1}$, & $E_{\mathrm{app}{ }^{0} \mathrm{ox} 2}$ \\
\hline 1 & - & +0.06 & +0.21 & +0.51 \\
2 & - & +0.03 & +0.14 & +0.45 \\
3 & - & -0.05 & +0.06 & +0.36 \\
4 & -1.05 & \multicolumn{2}{c}{+0.28} & +0.65
\end{tabular}

$E_{\text {app ox } 1}{ }^{0}=+0.28 \mathrm{~V}$ and $E_{\text {app }}{ }^{0}$ ox $2=+0.65 \mathrm{~V} \mathrm{vs} \mathrm{Fc}^{+} / \mathrm{Fc}$ corresponding to the successive generation of cation radical then dication species simultaneously on each TTF framework (Figure 3). This unique first two-electron oxidation step indicates that the two TTF units are electrochemically equivalent, thus excluding the presence of intra- or intermolecular electronic interactions between them. It should be noted that the electroactive naphthoquinone acceptor group incorporated in the spacer unit is char-

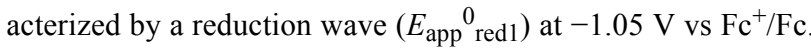
On the contrary, the CV of clips $\mathbf{1}-\mathbf{3}$ shows a significant splitting of the first oxidation wave ( $E_{\text {app }}{ }^{0}$ ox 1 and $\left.E_{\text {app ox1 }}{ }^{1}\right)$, suggesting the presence of intermolecular (between two clips) or intramolecular (within a clip) interactions between two TTF units (i.e., mixed valence and/or $\pi$-dimer) [41]. Eventually, the reversible two-electron process (i.e., $1 \mathrm{e}^{-}$on each $\mathrm{TTF}^{+\cdot}$ unit) for the second oxidation step ( $E_{\text {app }}{ }^{0}$ ox 2$)$ leading to fully oxidized TTF units is in accordance with independent $\mathrm{TTF}^{2+}$ states subject to repulsive electrostatic interactions. Such splitting phenomenon of the first oxidation wave has been previously reported by Azov et al. for TTF-containing molecular tweezers based on a 1,2,4,5-tetramethylbenzene scaffold $[42,43]$.

At this stage, one should keep in mind that the distance between two TTF sidewalls within clips $\mathbf{2}$ and $\mathbf{3}$ is quite important (8.2 $\AA$ and $7.4 \AA$, respectively). Such a distance, even though determined in the solid state, does not seem compatible to allow an intramolecular interaction to occur between two TTF units during the first oxidation step. In order to address this issue and to explore possible intermolecular (between two clips) interactions, concentration dependence electrochemical experiments were performed. Cyclic voltammograms were recorded using molecular clip 2 at different concentrations $\left(10^{-3} \mathrm{M}, 10^{-4} \mathrm{M}\right.$ and $\left.5 \times 10^{-5} \mathrm{M}\right)$ (Figure 4 ).

Importantly, whereas the splitting of the first oxidation wave was perfectly observed at high concentration $\left(10^{-3} \mathrm{M}\right)$, we noted that the phenomenon was significantly decreased at lower concentration. First, the absence of a splitting or broadening of the first oxidation process at low concentration informed us that the two TTF units are equivalent, thus excluding intramolecular interactions. Secondly, the concentration dependence and the splitting at higher concentrations provided evidence for the existence of intermolecular interactions and the formation of mixed-valence and radical cation dimer states. These results clearly demonstrated the presence of an intermolecular mixedvalence phenomenon.

According to these first results, the following model could be proposed in agreement with the successive oxidation steps in the CV of molecular clips $\mathbf{1}, \mathbf{2}$ and $\mathbf{3}$ (Scheme 3). Because the 

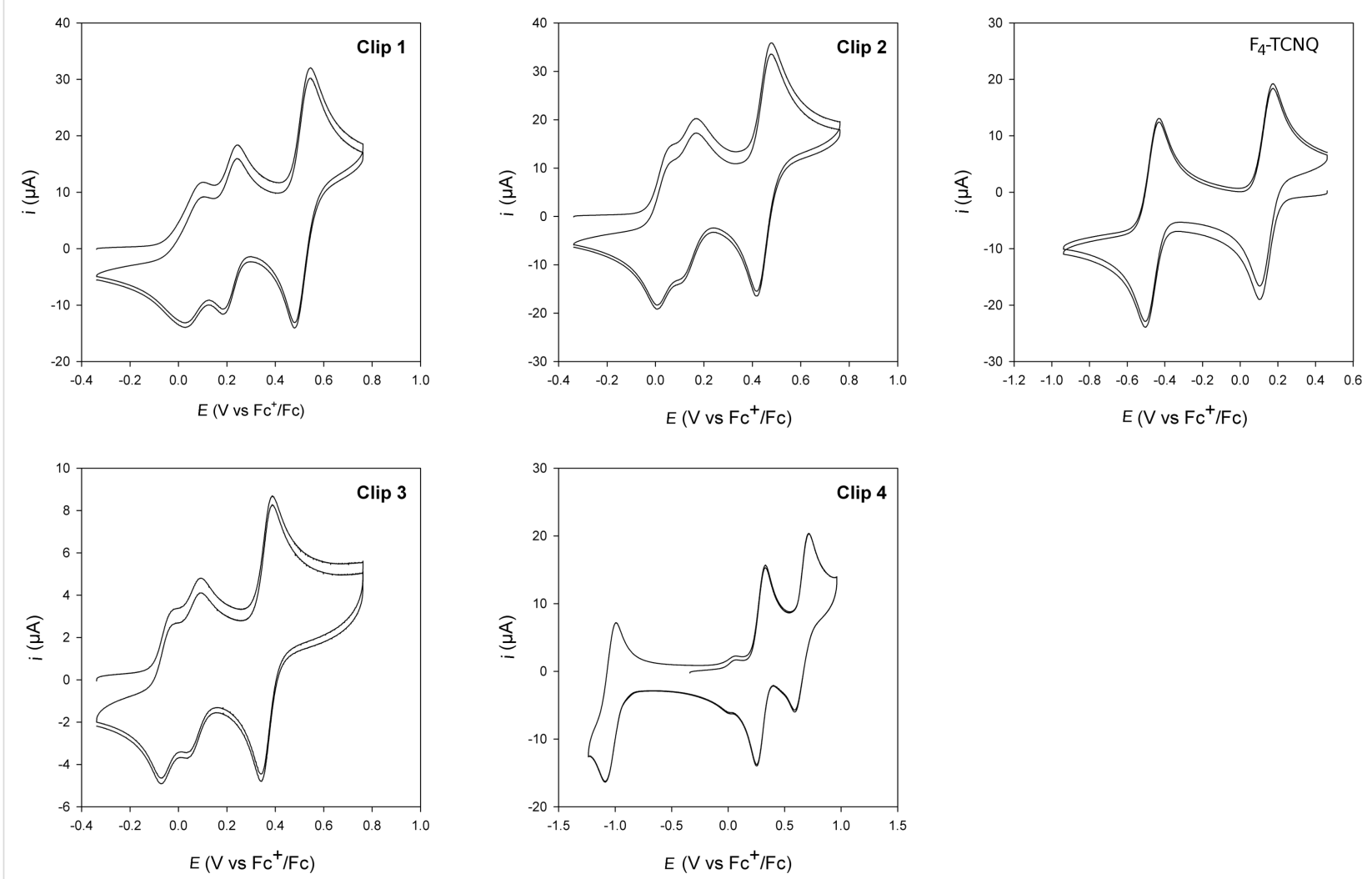

Figure 3: Cyclic voltammograms of molecular clips 1, 2, 3, 4 and $\mathrm{F}_{4}-\mathrm{TCNQ}$ at $10^{-3} \mathrm{M}$ in $0.1 \mathrm{M} \mathrm{TBAPF} / \mathrm{CH}_{2} \mathrm{Cl}_{2} / \mathrm{CH}_{3} \mathrm{CN}_{3: 1}$ on a glassy carbon electrode at $100 \mathrm{mV} \cdot \mathrm{s}^{-1}$.

two TTF units are equivalent, the first oxidation step of the clip involves a one-electron process on each TTF unit, leading to the clip bearing two radical cations. The concentration dependence shown on CVs suggested that this clip with two radical cations stack with and/or without self-assembly affording mixedvalence or $\pi$-dimer interactions. At higher potential, the tetra-
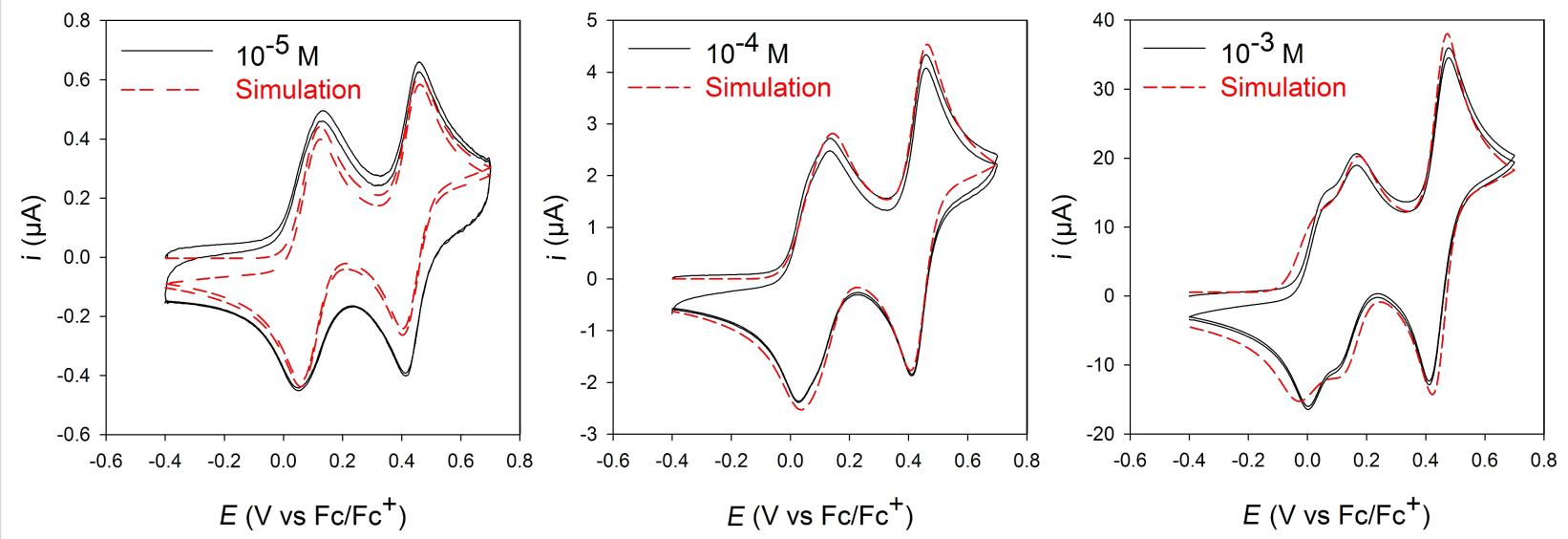

Figure 4: Cyclic voltammograms of molecular clip 2 at different concentrations (left: $10^{-5} \mathrm{M}$; middle: $10^{-4} \mathrm{M}$; right: $10^{-3} \mathrm{M}$ ) in $0.1 \mathrm{M}$ TBAPF $/ \mathrm{CH}_{2} \mathrm{Cl}_{2} /$ $\mathrm{CH}_{3} \mathrm{CN} 3: 1$ on a glassy carbon electrode at $100 \mathrm{mV} \cdot \mathrm{s}^{-1}$. Red dashed line: electrochemical simulation performed from experiments $\left(E_{1}=0.090 \mathrm{~V}\right.$, $E_{2}=0.165 \mathrm{~V}, E_{3}=0.435 \mathrm{mV}, K_{\mathrm{MV}}=11400 \mathrm{M}^{-1}, K_{\mathrm{DIM}}=680 \mathrm{M}^{-1}, k_{\mathrm{f}}=1 \times 10^{9} \mathrm{M}^{-1} \cdot \mathrm{s}^{-1}$ for all the forward reactions, $\alpha=0.5$ and $k_{\mathrm{s}}=0.01 \mathrm{~cm} \cdot \mathrm{s}^{-1}$ for all the charge transfers). 


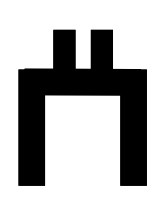

$-2 \mathrm{e}^{-}$
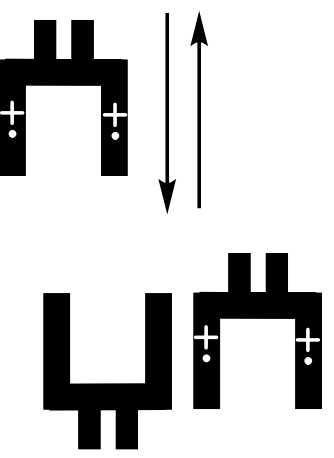

and/or

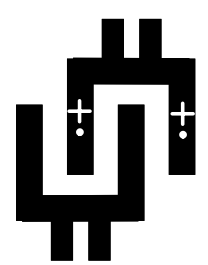

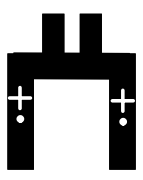

$-2 \mathrm{e}^{-}$
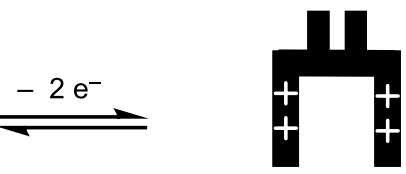
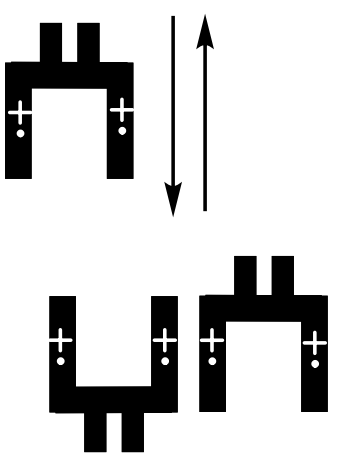

and/or

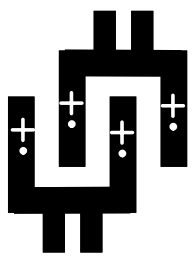

Scheme 3: Graphical representation of the stepwise oxidation of molecular clips 1, 2 and 3

cation is provided by another one-electron process on each TTF unit leading to a clip bearing two dications.

The graphical representation can be simulated by an electrochemical simulation program (DigiElch 7) involving an electrochemical mechanism (Scheme 4) composed by three one-electron processes and two charge-coupled chemical reactions (i.e., formation of mixed-valence and dimerization via a square scheme). Due to the equivalence of the two TTF units, it is important to note that the input value of the concentration of $\mathrm{D}$ in Scheme 4 (D represents one TTF unit of the clip) must be twice that of the experimental concentration of a molecular clip. The good agreement between experimental data and modelled CVs over the whole range of concentration supports the graphical representation of the stepwise oxidation of molecular clips 1, 2 and 3 (Scheme 3).

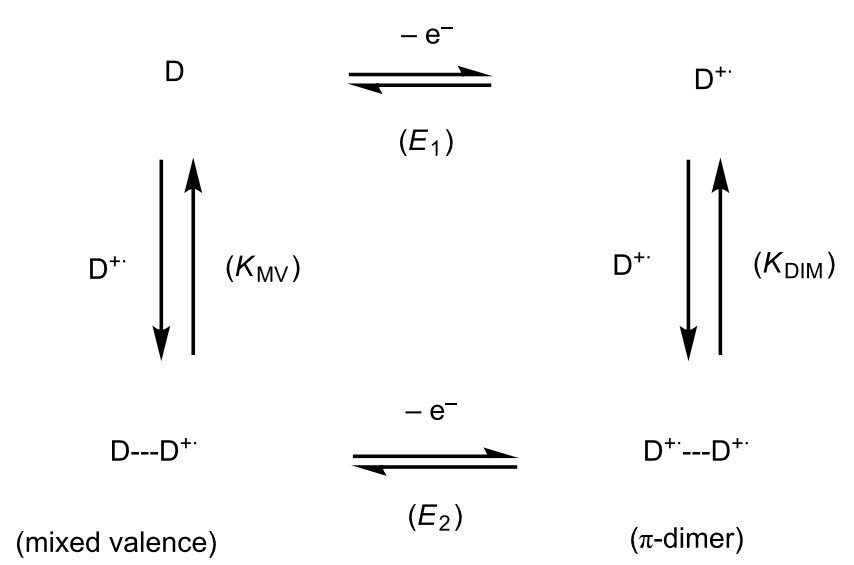

Scheme 4: Electrochemical mechanism used to simulate the CVs of molecular clips 1, 2 and 3. 


\section{Optical and spectroelectrochemical properties}

The optical properties of oxidized states of molecular clip 1 were monitored by UV-vis-NIR spectroscopy, by successive aliquot addition of $\mathrm{NOSbF}_{6}\left(5 \times 10^{-3} \mathrm{M}\right.$ in $\left.\mathrm{CH}_{3} \mathrm{CN}\right)$ used as

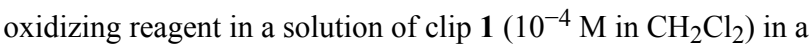
quartz cell $(0.2 \mathrm{~cm})$ (Figure 5). Clip 1 bearing methoxycarbonyl groups at the periphery of the TTF framework was chosen because, to our knowledge, the optical characteristics of such a TTF derivative have not been yet reported. The redox potential $\left(+0.87 \mathrm{~V} \mathrm{vs} \mathrm{Fc}^{+} / \mathrm{Fc}\right)$ of the $\mathrm{NOSbF}_{6}$ reagent is in agreement to allow the oxidation of TTF units. Chemical oxidation led to the rapid disappearance of the band at $320 \mathrm{~nm}$ attributed to the neutral TTF derivative and to the concomitant development of new bands characteristic for the cation radical and/or the $\pi$-dimer $(440,595 \mathrm{~nm})$, bands which are characteristic for substituted TTF derivatives. After addition of nearly two equivalents of oxidizing reagent, we noted the appearance of the absorption band characteristic of the formation of the TTF dication $(340 \mathrm{~nm})$. As soon as we started to add aliquots of $\mathrm{NOSbF}_{6}$ oxidant onto molecular clip $\mathbf{1}$, we could observe in the NIR region an absorption band centered at approximately $815 \mathrm{~nm}$ and a broad and weak band between 1300-2000 nm.

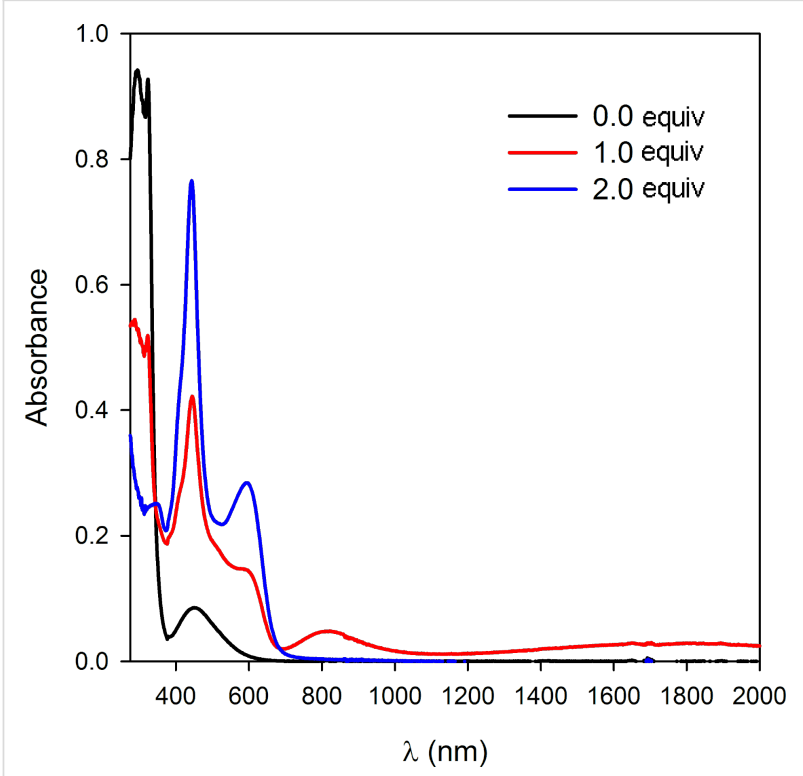

Figure 5: Chemical oxidation of molecular clip $1\left(10^{-4} \mathrm{M}, \mathrm{CH}_{2} \mathrm{Cl}_{2}\right)$ using aliquots of $\mathrm{NOSbF}_{6}$ oxidizing reagent $\left(5 \times 10^{-3} \mathrm{M}, \mathrm{CH}_{3} \mathrm{CN}\right)$.

Known to be a powerful tool for analyzing the formation of $\pi$-dimers (DIM) and mixed-valence (MV) systems, time resolved spectroelectrochemical experiments [44-46] were performed on molecular clip 1 in order to probe the first oxidation step at two different concentrations between 350 and $1700 \mathrm{~nm}$ in $0.1 \mathrm{M} \mathrm{TBAPF} / \mathrm{CH}_{2} \mathrm{Cl}_{2} / \mathrm{CH}_{3} \mathrm{CN}$ (3:1). At
$5 \times 10^{-5} \mathrm{M}$, only two absorption bands (i.e., 450 and $600 \mathrm{~nm}$ ) were observed (Figure 6). Confirming a concentration dependence, the absorbance profile at $5 \times 10^{-4} \mathrm{M}$ was different from the one obtained at $5 \times 10^{-5} \mathrm{M}$. Two additional absorption bands simultaneously emerged at the beginning of the oxidation process and the end of the reduction process: one at $825 \mathrm{~nm}$ and a broad band in near infrared range beyond $1300 \mathrm{~nm}$ (Figure 6).

In agreement with the simulated concentration-time profiles in thin layer conditions (Figure 6 - bottom), the appearance of the absorption bands centered around 825 and beyond $1300 \mathrm{~nm}$ were attributed to the formation of $\left[(\mathrm{TTF})_{2}\right]^{+}$mixed-valence dimer $[47,48]$ and the absorption bands centered around $600 \mathrm{~nm}$ to the $\left(\mathrm{TTF}^{\cdot+}\right)_{2} \pi$-dimer [49]. The band close to $825 \mathrm{~nm}$ could be assigned to cation radicals stack with self-assembly affording mixed-valence. Nevertheless, at this stage, it would be premature to conclude with certainty. The origin of this band is currently under investigation and requires complementary studies to carry out on different substituted molecular clips.

By analogy with unsubstituted TTF derivative, these three bands reasonably support the presence of mixed-valence and cation radical dimers during the oxidation process. Whereas the phenomenon of dimer formation of the TTF cation radical is commonly observed in the solid state, it was also described in solution at low temperature in a concentrated TTF solution [50], or at room temperature in a dilute solution. In the latter case, the characterization of $\left[(\mathrm{TTF})_{2}\right]^{+\cdot}$ mixed-valence dimer and/or $\left(\mathrm{TTF}^{+\cdot}\right)_{2}$ dimer species concerned systems for which the dimer stabilization is resulting from the close proximity of the two TTF units. That is the case for conjugated bisTTF systems [51], bisTTF-substituted calix[4] arenes [52], or supramolecular architectures such as [3]catenane [53], cucubit[8] uril [54] or selfassembled cages [55] which facilitate the formation of TTF dimers.

Studying the glycoluril-based molecular clip $\mathbf{1 5}$ presenting also TTF sidewalls [56,57], Chiu et al. have observed the mixedvalence and radical cation dimer states at high concentration $\left(10^{-3} \mathrm{M}\right)$ and at room temperature [58]. Indeed, the CV of molecular clip 15 exhibited four consecutive oxidation waves, which were interpreted by a succession of oxidation processes of the TTF sidewalls (Figure 7). These dimer interactions were predicted to exist at room temperature by theoretical investigation realized on this system [59].

By comparison with these results observed for molecular clip 15 [58], it is clear that clips $\mathbf{1 - 3}$ exhibit $\left[(\mathrm{TTF})_{2}\right]^{+\cdot}$ mixedvalence dimer and/or $\left(\mathrm{TTF}^{+\cdot}\right)_{2}$ dimer species but their selfassociation organization could not be yet demonstrated. The 


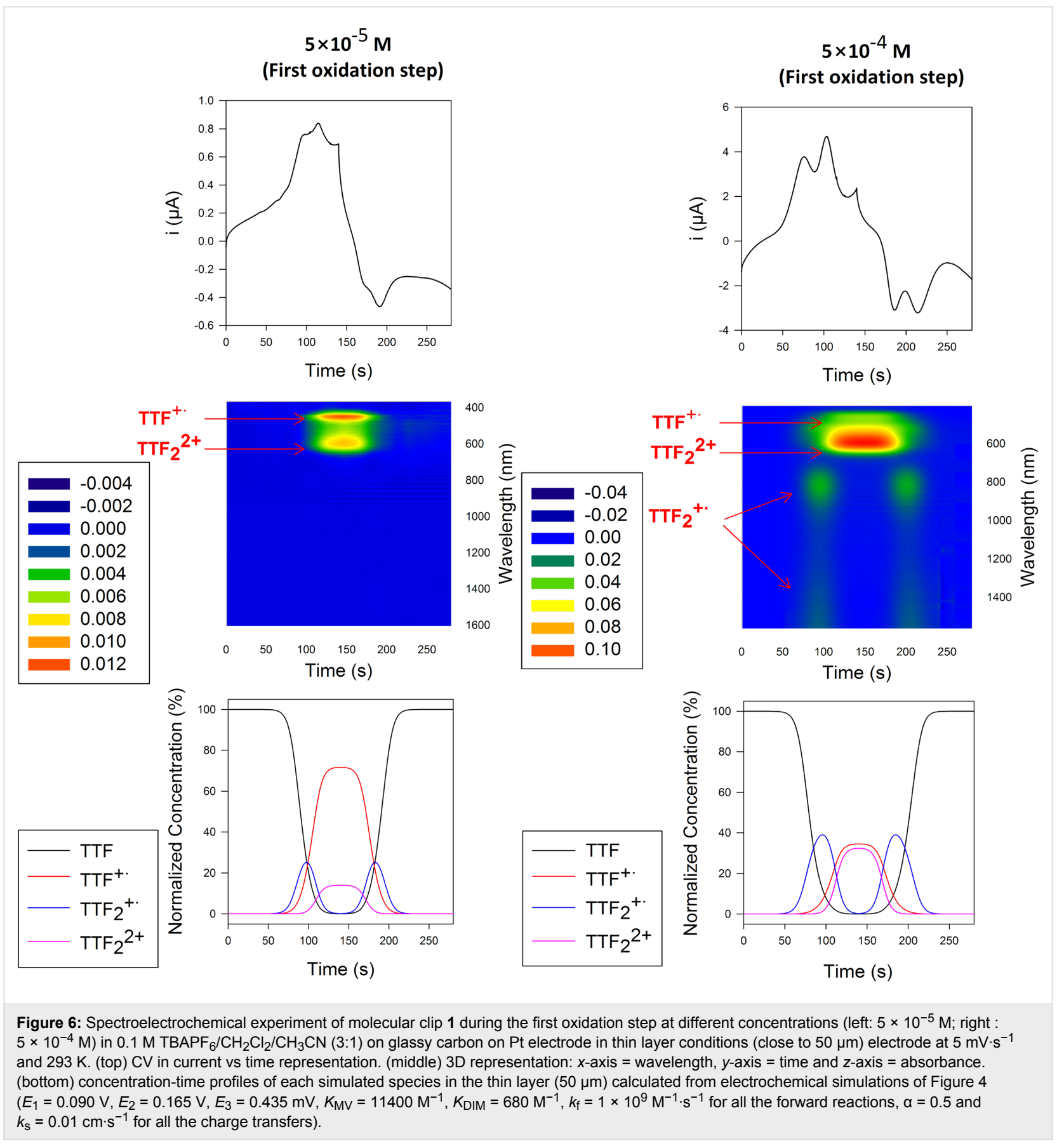

presence of more or less sterically bulky groups at the periphery of the TTF moieties does not provide an advantage for the selfassembly of dimers. Moreover, this dimerization phenomenon which is driven by the inclusion of one sidewall into the cavity of the opposing clip is not observed in the solid state for clips 2 and 3 (Figure 8). This typical packing arrangement was previously observed in many cases of glycoluril-based molecular clips containing two aromatic sidewalls [26,60-63]. On the contrary, considering the unit cell for single crystals of clip $\mathbf{2}$, $\mathrm{X}$-ray analysis showed that two neighboring molecules of clip $\mathbf{2}$ appeared in a head-to-tail arrangement and short TTF $\cdots$ TTF intermolecular distances $(3.51 \AA)$ were determined between two clips in the solid state.

\section{Binding properties}

In order to establish the influence of electronic and spatial properties of the clips towards binding ability of neutral electrodeficient guest molecules, we have chosen compounds $\mathbf{3}$ and $\mathbf{4}$ for this study. Molecular clip 3 presents better $\pi$-donating ability according to CV study and a smaller interplanar TTF distance 

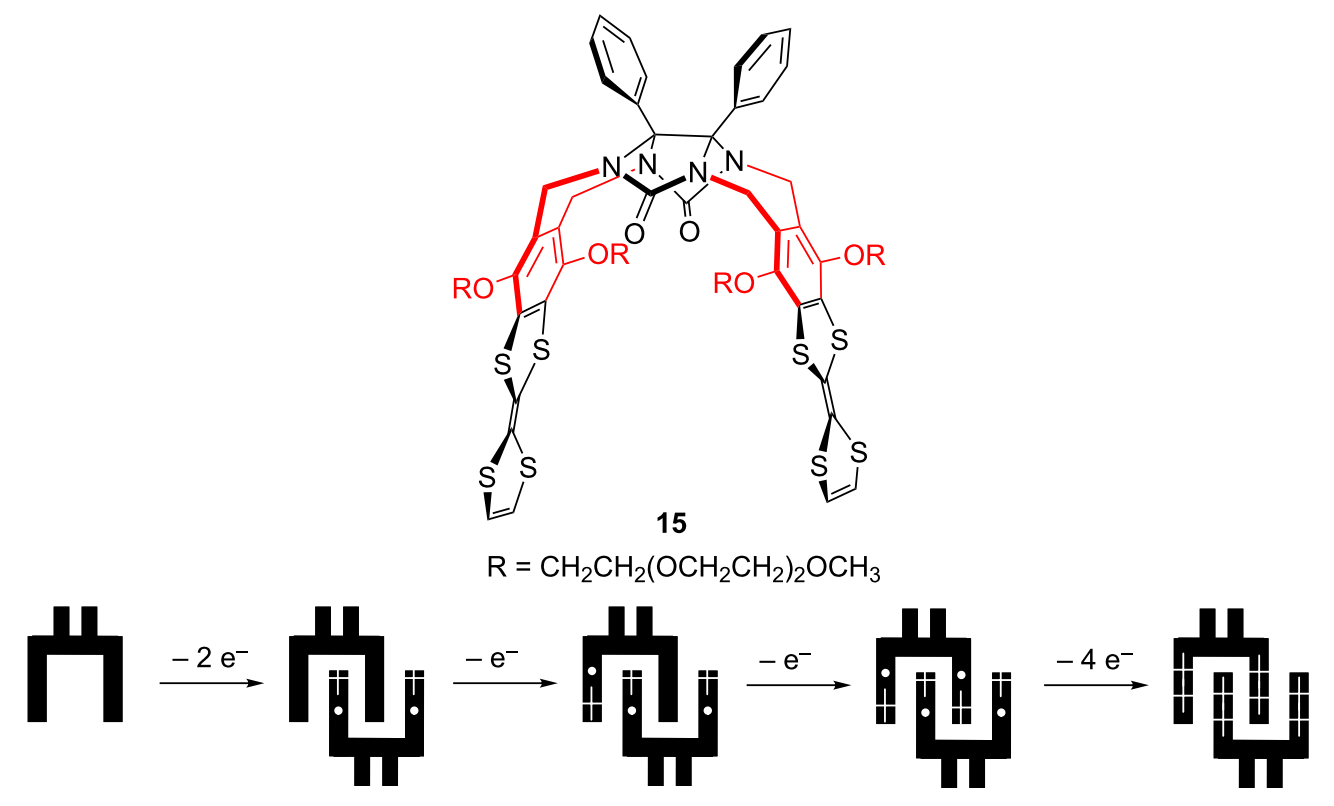

Figure 7: Molecular structure of molecular clip 15 and representation of its stepwise oxidation processes proposed by Chiu et al. [58].

(7.41 $\AA$ compared to calculated $9.2 \AA$ for clip 4). Binding properties were studied using 1,3-dinitrobenzene $(m$-DNB) as a weak and small aromatic electron acceptor molecule. It should be noted that Nolte et al. have successfully observed the com- plexation of $m$-DNB using a glycoluril-based receptor bearing 2,7-dimethoxynaphthalene walls $\left(K_{\mathrm{a}}=(115 \pm 10) \mathrm{M}^{-1}\right)$ [64]. In the latter case, it was proposed that binding was occurring through an induced-fit mechanism with a recognition process on
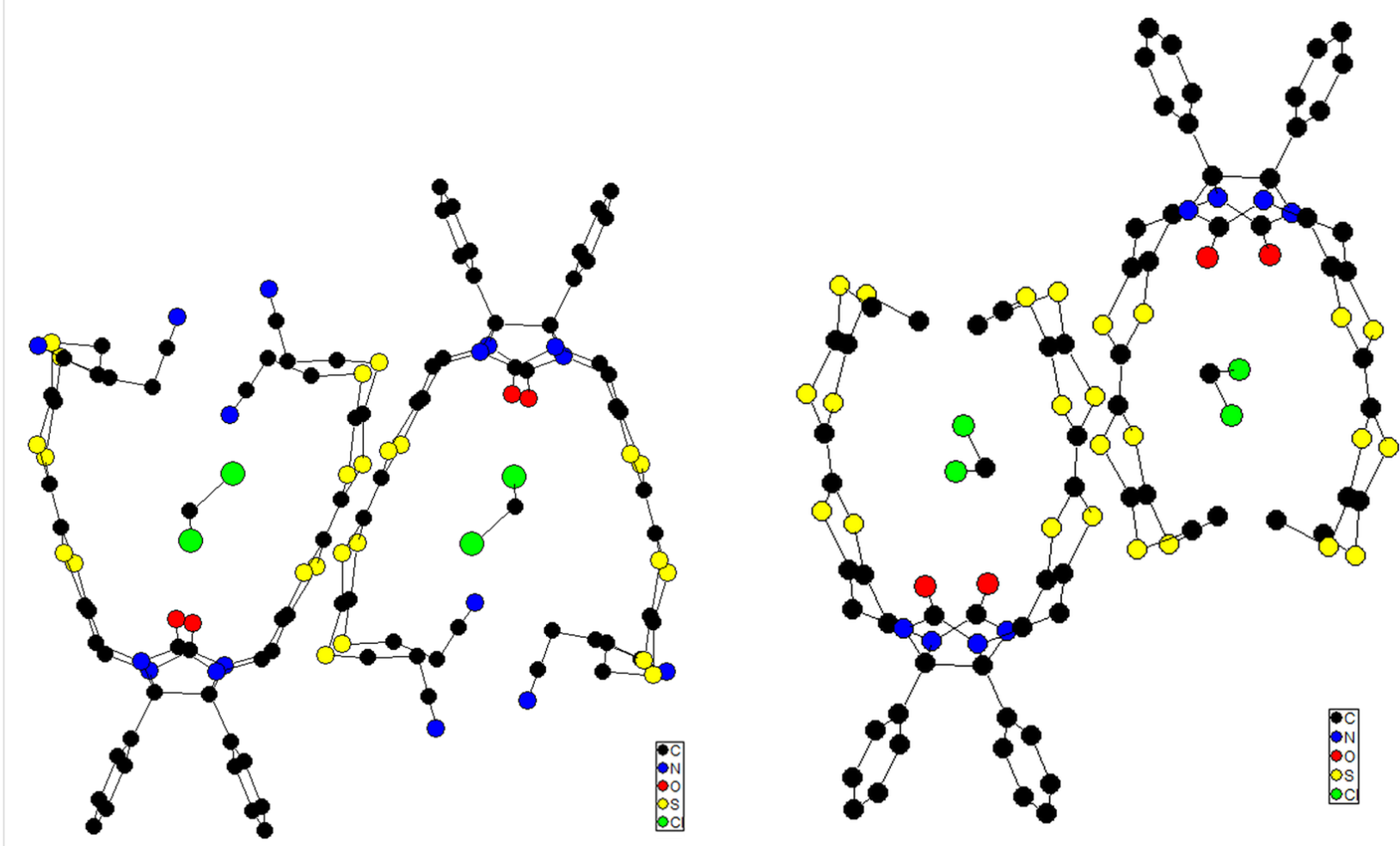

Figure 8: Molecular packing diagram of clips 2 (left) and $\mathbf{3}$ (right) obtained from X-ray analysis. A molecule of $\mathrm{CH}_{2} \mathrm{Cl}_{2}$ is included inside the cavity of each clip. Hydrogen atoms are omitted for clarity. 
the basis of the size rather than the acceptor strength. We can suppose that the presence of stronger $\pi$-donor TTF sidewalls in clip 3 favorize donor-acceptor interactions and consequently the binding properties towards $m$-DNB. We have also checked the influence of the redox properties towards binding ability by studying the strong electrodeficient acceptor $\mathrm{F}_{4}$-TCNQ.

\section{Interaction with 1,3-dinitrobenzene ( $m$-DNB)}

The host-guest affinity was detected by UV-visible spectroscopy upon titration of clip $3\left(10^{-3} \mathrm{M}\right.$ in $\left.o-\mathrm{C}_{6} \mathrm{H}_{4} \mathrm{Cl}_{2}\right)$ with addition of $m$-DNB $\left(10^{-1} \mathrm{M}\right.$ in $\left.o-\mathrm{C}_{6} \mathrm{H}_{4} \mathrm{Cl}_{2}\right)$ aliquots. No additional change of the spectra was observed after the addition of one equivalent of $m$-DNB $\left(-1.30 \mathrm{~V} \mathrm{vs} \mathrm{Fc}^{+} / \mathrm{Fc}\right)$ [65] which is in agreement with the formation of a 1:1 complex. A Job plot carried out in $o-\mathrm{C}_{6} \mathrm{H}_{4} \mathrm{Cl}_{2}$ between clip 3 and $m$-DNB shows a maximum at 0.5 , confirming the formation of the $1: 1$ complex (m-DNB@clip 3) (Figure 9 left). The association constant was determined to be $K_{\mathrm{a}}=(7 \pm 3) \times 10^{3} \mathrm{M}^{-1}$ by exploiting the Job plot analysis according to literature [66]. Despite many efforts devoted to the search for a complexation of $m$-DNB using molecular clip 4, we could not observe any host-guest binding interaction. These results suggest that electronic and spatial properties of the cavity constitute fundamental parameters for binding the $m$-DNB guest. The binding of such a weak electron acceptor was successful for molecular clip 3 presenting the most suitable intramolecular distance between TTF sidewalls and the strongest $\pi$-donor ability.

\section{Interaction with tetrafluoroquinodimethane $\left(\mathrm{F}_{4}-\mathrm{TCNQ}\right)$}

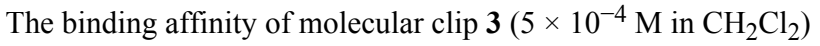
was studied by a UV-visible titration with the electron acceptor
$\mathrm{F}_{4}$-TCNQ $\left(10^{-5} \mathrm{M}\right.$ in $\left.\mathrm{CH}_{2} \mathrm{Cl}_{2}\right)$. Addition of aliquots of molecular clip 3 onto a $\mathrm{F}_{4}$-TCNQ solution showed the presence of an isosbestic point at $395 \mathrm{~nm}$ with the concomittent formation and increase of bands at 760 and $860 \mathrm{~nm}$ which could be attributed to the progressive formation of the $\mathrm{F}_{4}$-TCNQ radical anion (Figure 10) [67,68]. The increase of the bands around 750 and $850 \mathrm{~nm}$ was attributed to the cumulative contribution of the increasing formation of TTF cation radical species and the $\mathrm{F}_{4}$-TCNQ anion radical.

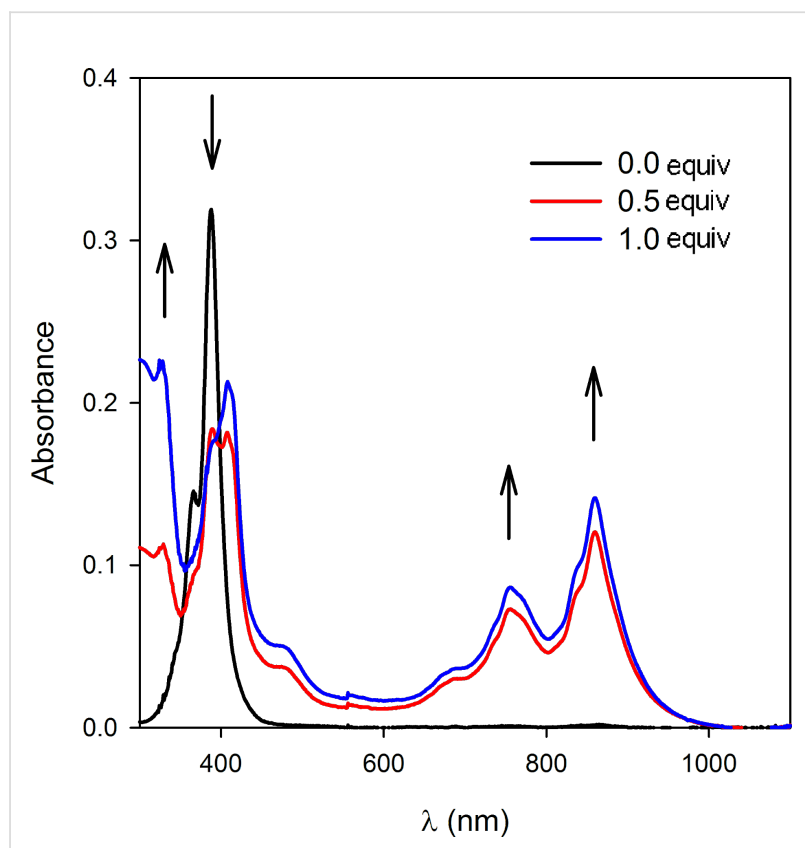

Figure 10: UV-visible absorption spectra of $\mathrm{F}_{4}-\mathrm{TCNQ}\left(\mathrm{CH}_{2} \mathrm{Cl}_{2}\right.$, $\left.10^{-5} \mathrm{M}\right)$ upon titration with molecular clip $3\left(\mathrm{CH}_{2} \mathrm{Cl}_{2}, 5 \times 10^{-4} \mathrm{M}\right)$.
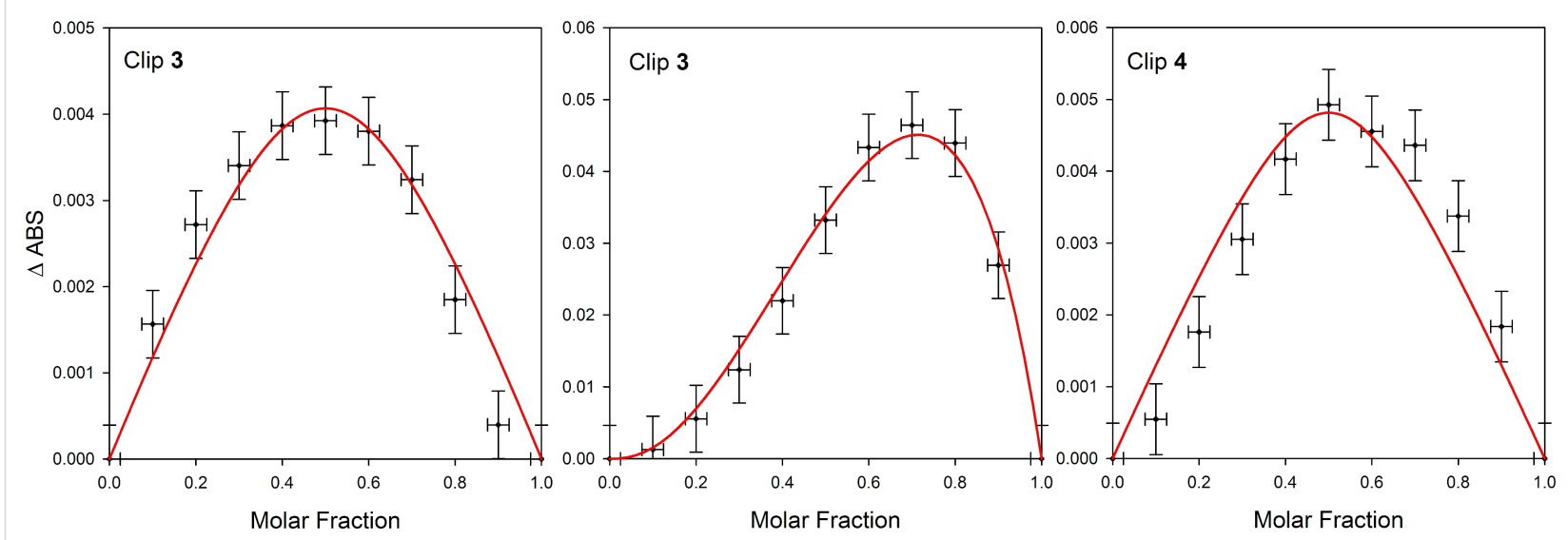

Figure 9: Left: Job plot analysis for DNB vs molecular clip 3 ([3 + DNB] $=10^{-3} \mathrm{M}$ in o- $\mathrm{C}_{6} \mathrm{H}_{4} \mathrm{Cl}_{2}$ at 800 nm) at room temperature. Middle: Job plot for $\mathrm{F}_{4}$-TCNQ vs molecular clip 3 at room temperature $\left(\left[3+\mathrm{F}_{4}-\mathrm{TCNQ}\right]=10^{-5} \mathrm{M}\right.$ in $\mathrm{CH}_{2} \mathrm{Cl}_{2}$ at $860 \mathrm{~nm}$ ) consistent with a $2: 1$ binding stoichiometry. Right: Job plot for $\mathrm{F}_{4}-\mathrm{TCNQ}$ vs molecular clip 4 at room temperature $\left(\left[4+\mathrm{F}_{4}-\mathrm{TCNQ}\right]=10^{-5} \mathrm{M} \mathrm{CH}_{2} \mathrm{Cl}_{2}\right.$ at $\left.860 \mathrm{~nm}\right)$ in agreement with a $1: 1$ binding stoichiometry. 
A Job plot carried out in $\mathrm{CH}_{2} \mathrm{Cl}_{2}$ between clip 3 and $\mathrm{F}_{4}$-TCNQ exhibited a maximum at around 0.7 , a finding that corroborates with the formation of a 1:2 complex ( $\mathrm{F}_{4}$-TCNQ) $)_{2} @$ clip 3 (Figure 9 middle) with an average binding constant of $K_{\mathrm{a}}=(8 \pm 5) \times 10^{8} \mathrm{M}^{-1}$.

Similar studies were carried out using molecular clip $\mathbf{4}$ and quantitative measurements were performed using UV-visible titration considering the changes in the spectra of $\mathrm{F}_{4}$-TCNQ at $860 \mathrm{~nm}$ upon addition of sensor 4 . The construction of the Job plot is in agreement with the 1:1 binding stoichiometry between clip 4 and $\mathrm{F}_{4}$-TCNQ with a maximum centered at a molar ratio of 0.5 (Figure 9 right). The high association constant $K_{\mathrm{a}}=(1.3 \pm 0.8) \times 10^{6} \mathrm{M}^{-1}$ in $\mathrm{CH}_{2} \mathrm{Cl}_{2}$ confirms that this rigidified molecular clip 4 is an efficient receptor for $\mathrm{F}_{4}$-TCNQ guest electron acceptor.

This difference in binding interaction between host molecular clips 3 and $\mathbf{4}$ towards the $\mathrm{F}_{4}$-TCNQ guest could be explained by their electrochemical properties. By comparing the first oxidation potential of clips 3 and $\mathbf{4}$ with the first reduction potential of $\mathrm{F}_{4}$-TCNQ $\left(E_{\text {app }}{ }^{0}\right.$ red1 $=+0.14 \mathrm{~V} \mathrm{vs} \mathrm{Fc}^{+} / \mathrm{Fc}-$ Figure 3$)$, it is clear that $\mathrm{F}_{4}$-TCNQ guest presents a high reduction potential, sufficient to allow the oxidation of molecular clip 3. Consequently, the $\left(\mathrm{F}_{4}-\mathrm{TCNQ}\right)_{2} @$ clip 3 complex should result from a redox interaction between the host and the guest. On the other hand, the oxidation potential of molecular clip 4 is increased due to the introduction of the naphthoquinone spacer. Consequently, the corresponding 1:1 stoichiometry should reasonably correspond to the binding of $\mathrm{F}_{4}$-TCNQ inside the cavity of clip 4 (Figure 11). This binding of $\mathrm{F}_{4}$-TCNQ also results from favourable spatial parameters with the increase of the intramolecular distance between the two TTF sidewalls. Thanks to the good $\pi$-donor ability of the TTF sidewalls, in combination with a well-suited size of the cavity, it is here demonstrated that molecular clip 4 constitutes one of the rare examples of systems exhibiting good affinity for sandwiching $\mathrm{F}_{4}$-TCNQ as an electron poor guest.

\section{Conclusion}

We have presented original synthetic strategies leading to glycoluril-based molecular clips containing electroactive TTF sidewalls. In particular, the one-step preparation of molecular clip using the N-tetraalkylation of glycoluril constitutes a powerful versatile method allowing an easy access to new architectures for which electrochemical properties can be tuned by simple modification of peripheral substituents on the TTF moiety. Cyclic voltammetry and spectroelectrochemical measurements demonstrated that the mixed-valence state in these fused glycoluril-TTF molecular clips seems to originate from intermolecular TTF interactions, according to measurements at various concentrations and to cyclic voltammogram simulations. Spatial and electrochemical properties were shown to be fundamental parameters towards the binding interaction of a weak $\left(m\right.$-DNB) or strong $\left(\mathrm{F}_{4}\right.$-TCNQ) electrodeficient guest. Consequently, the selectivity for a given target guest could be precisely tuned via the choice of the molecular clip according to its electrochemical and spatial considerations.

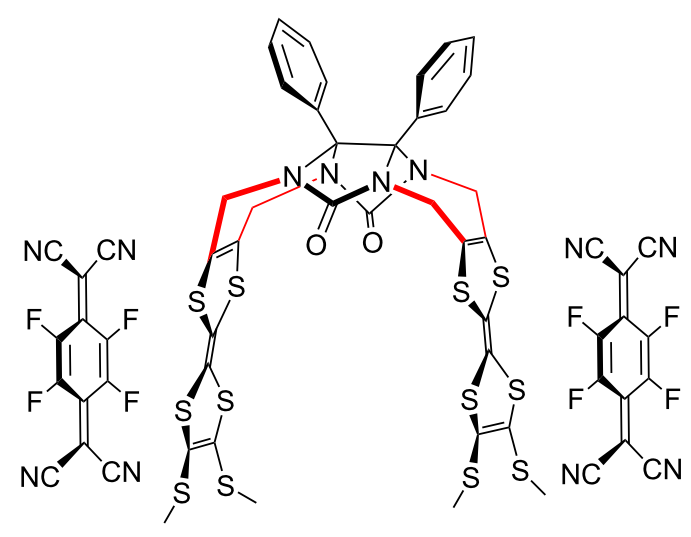

3

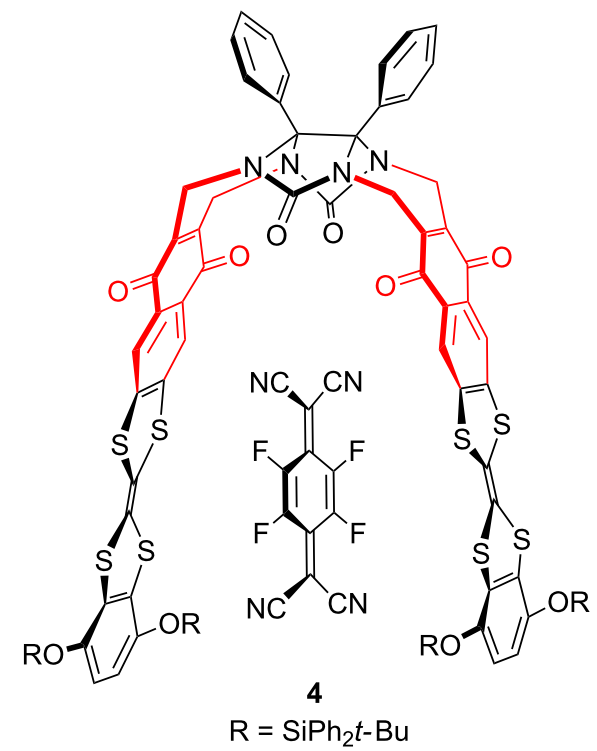

Figure 11: Redox interaction (left) and complexation (right) of $\mathrm{F}_{4}-\mathrm{TCNQ}$ with molecular clips 3 and 4 . 


\section{Experimental Synthesis}

Molecular clips 1-3 [18] and 4 [19] were synthesized according to our previous reports.

\section{Electrochemical and spectroelectrochemical experiments}

Electrochemistry and time-resolved spectroelectrochemistry in solution were performed using the already described home selfmade cell $[44,45]$. Electrochemical measurements were carried out using a platinum wire counter electrode and a silver wire as a quasi-reference electrode with a Biologic SP-150 potentiostat driven by the EC-Lab software including ohmic drop compensation. Experiments were recorded in dry HPLC-grade acetonitrile and dichloromethane with tetrabutylammonium hexafluorophosphate $\left(\mathrm{Bu}_{4} \mathrm{NPF}_{6}\right.$, electrochemical grade, Fluka) as supporting electrolyte. All solutions were prepared and transferred into the spectroelectrochemical cell in a glove box containing dry, oxygen-free $(<1 \mathrm{ppm})$ argon, at room temperature.

Spectrophotometric measurements were carried out in direct reflexing mode on the working electrode (i.e., Pt or glassy carbon) with a homemade bench composed of different Princeton Instruments modules (light sources, fibers, monochromators, spectroscopy camera and software). The connection between the light source, the cell and the spectrophotometer is ensured through a "Y-shaped" optical fiber bundle: 18 fibers guide the light to the cell, and 19 fibers collect the reflected light from the cell to visible (320-1080 nm / maximum acquisition frequency $2 \mathrm{MHz}$ ) and IR (900-1700 nm / maximum acquisition frequency $8 \mathrm{MHz}$ ) CCD detectors. The sensitivity of the spectroscopic measurement $(<3$ electrons at $100 \mathrm{kHz}$ and $<13$ electrons at $2 \mathrm{MHz}$ between 320 and $1080 \mathrm{~nm}$; 400 electrons (high gain) and 5000 electrons (low gain) between $900 \mathrm{~nm}$ and $1700 \mathrm{~nm}$ ) allows performing a spectroelectrochemistry experiment under the usual conditions of electrochemistry.

\section{Acknowledgements}

This work was supported by the Ministère de la Recherche et de l'Enseignement Supérieur for Ph.D grants to Y. Cotelle and M. Hardouin-Lerouge.

\section{References}

1. Wudl, F.; Smith, G. M.; Hufnagel, E. J. J. Chem. Soc. D 1970, 1453-1454. doi:10.1039/C29700001453

2. Bryce, M. R. J. Mater. Chem. 2000, 10, 589-598. doi:10.1039/A908385E

3. Segura, J. L.; Martín, N. Angew. Chem., Int. Ed. 2001, 40, 1372-1409. doi:10.1002/1521-3773(20010417)40:8<1372::AID-ANIE1372>3.0.CO; 2-I
4. Yamada, J.; Sugimoto, T., Eds. TTF Chemistry. Fundamentals and applications of tetrathiafulvalene; Springer Verlag: New York, 2004.

5. Gorgues, A.; Hudhomme, P.; Sallé, M. Chem. Rev. 2004, 104, 5151-5184. doi:10.1021/cr0306485

6. Batail, P., Ed. Special issue on Molecular Conductors. Chem. Rev. 2004, 104, 4887-5782.

7. Martín, N. Chem. Commun. 2013, 49, 7025-7027 doi:10.1039/C3CC00240C

8. Bendikov, M.; Wudl, F.; Perepichka, D. F. Chem. Rev. 2004, 104, 4891-4946. doi:10.1021/cr030666m

9. Bergkamp, J. J.; Decurtins, S.; Liu, S.-X. Chem. Soc. Rev. 2015, 44, 863-874. doi:10.1039/C4CS00255E

10. Nielsen, M. O.; Lomholt, C.; Becher, J. Chem. Soc. Rev. 2000, 29, 153-164. doi:10.1039/A803992E

11. Canevet, D.; Sallé, M.; Zhang, G.; Zhang, D.; Zhu, D. Chem. Commun. 2009, 2245-2269. doi:10.1039/B818607N

12. Steed, J. W.; Atwood, J. L. Supramolecular Chemistry, 2nd ed.; John Wiley \& Sons Ltd, 2009.

13. Hardouin-Lerouge, M.; Hudhomme, P.; Sallé, M. Chem. Soc. Rev. 2011, 40, 30-43. doi:10.1039/b915145c

14. Chen, C.-W.; Whitlock, H. W., Jr. J. Am. Chem. Soc. 1978, 100, 4921-4922. doi:10.1021/ja00483a063

15. Leblond, J.; Petitjean, A. ChemPhysChem 2011, 12, 1043-1051. doi:10.1002/cphc.201001050

16. Sijbesma, R. P.; Nolte, R. J. M. Top. Curr. Chem. 1995, 175, 25-56. doi:10.1007/3-540-58800-0_17

17. Rowan, A. E.; Elemans, J. A. A. W.; Nolte, R. J. M. Acc. Chem. Res. 1999, 32, 995-1006. doi:10.1021/ar9702684

18. Cotelle, Y.; Allain, M.; Legoupy, S.; Hudhomme, P. Org. Lett. 2014, 16, 2590-2593. doi:10.1021/ol500458e

19. Hardouin-Lerouge, M.; Cotelle, Y.; Legoupy, S.; Hudhomme, P. New J. Chem. 2014, 38, 5341-5348. doi:10.1039/c4nj00617h

20. Butler, A. R.; Leitch, E. J. Chem. Soc., Perkin Trans. 2 1980, 103-105. doi:10.1039/P29800000103

21. Hudhomme, P.; Le Moustarder, S.; Durand, C.; Gallego-Planas, N.; Mercier, N.; Blanchard, P.; Levillain, E.; Allain, M.; Gorgues, A.; Riou, A. Chem. - Eur. J. 2001, 7, 5070-5083. doi:10.1002/1521-3765(20011203)7:23<5070::AID-CHEM5070>3.0.C $0 ; 2-6$

22. Reek, J. N. H.; Kros, A.; Nolte, R. J. M. Chem. Commun. 1996, 245-247. doi:10.1039/CC9960000245

23. Elemans, J. A. A. W.; Rowan, A. E.; Nolte, R. J. M. J. Am. Chem. Soc. 2002, 124, 1532-1540. doi:10.1021/ja012061i

24. Creaven, B. S.; Gallagher, J. F.; McDonagh, J. P.; McGinley, J.; Murray, B. A.; Whelan, G. S. Tetrahedron 2004, 60, 137-143. doi:10.1016/j.tet.2003.10.084

25. Wu, A.; Chakraborty, A.; Witt, D.; Lagona, J.; Damkaci, F.; Ofori, M. A.; Chiles, J. K.; Fettinger, J. C.; Isaacs, L. J. Org. Chem. 2002, 67, 5817-5830. doi:10.1021/jo0258958

26. Wang, Z.-G.; Zhou, B.-H.; Chen, Y.-F.; Yin, G.-D.; Li, Y.-T.; Wu, A.-X.; Isaacs, L. J. Org. Chem. 2006, 71, 4502-4508. doi:10.1021/jo0603375

27. Bogaschenko, T. Yu.; Lyapunov, A. Yu.; Kikot, L. S.; Mazepa, A. V.; Botoshansky, M. M.; Fonari, M. S.; Kirichenko, T. I. Tetrahedron 2012, 68, 4757-4764. doi:10.1016/j.tet.2012.04.009

28. Easton, D. B. J.; Leaver, D. Chem. Commun. 1965, 585-586. doi:10.1039/C19650000585

29. Fabre, J.-M. Chem. Rev. 2004, 104, 5133-5150. doi:10.1021/cr0306440

30. Svenstrup, N.; Rasmussen, K. M.; Hansen, T. K.; Becher, J. Synthesis 1994, 809-812. doi:10.1055/s-1994-25580 
31. Simonsen, K. B.; Becher, J. Synlett 1997, 1211-1220. doi:10.1055/s-1997-1001

32. Hudhomme, P.; Liu, S.-G.; Kreher, D.; Cariou, M.; Gorgues, A. Tetrahedron Lett. 1999, 40, 2927-2930. doi:10.1016/S0040-4039(99)00325-1

33. Smeets, J. W. H.; Sijbesma, R. P.; Van Dalen, L.; Spek, A. L.; Smeets, W. J. J.; Nolte, R. J. M. J. Org. Chem. 1989, 54, 3710-3717. doi:10.1021/jo00276a037

34. Butler, A. R.; Hussain, I. J. Chem. Soc., Perkin Trans. 2 1981, 310-316. doi:10.1039/P29810000310

35. Sijbesma, R. P.; Kentgens, A. P. M.; Lutz, E. T. G.; van der Maas, J. H.; Nolte, R. J. M. J. Am. Chem. Soc. 1993, 115, 8999-9005. doi:10.1021/ja00073a015

36. Baffreau, J.; Dumur, F.; Hudhomme, P. Org. Lett. 2006, 8, 1307-1310. doi:10.1021/ol060011i

37. Gautier, N.; Mercier, N.; Riou, A.; Gorgues, A.; Hudhomme, P. Tetrahedron Lett. 1999, 40, 5997-6000. doi:10.1016/S0040-4039(99)01162-4

38. Kreher, D.; Liu, S.-G.; Cariou, M.; Hudhomme, P.; Gorgues, A.; Mas, M.; Veciana, J.; Rovira, C. Tetrahedron Lett. 2001, 42, 3447-3450. doi:10.1016/S0040-4039(01)00494-4

39. Hudhomme, P. C. R. Chim. 2006, 9, 881-891. doi:10.1016/j.crci.2005.11.008

40. Bénard, C. P.; Geng, Z.; Heuft, M. A.; VanCrey, K.; Fallis, A. G. J. Org. Chem. 2007, 72, 7229-7236. doi:10.1021/jo0709807

41. Spanggaard, H.; Prehn, J.; Nielsen, M. B.; Levillain, E.; Allain, M.; Becher, J. J. Am. Chem. Soc. 2000, 122, 9486-9494. doi:10.1021/ja000537c

42. Azov, V. A.; Gómez, R.; Stelten, J. Tetrahedron 2008, 64, 1909-1917. doi:10.1016/j.tet.2007.11.110

43. Skibiński, M.; Gómez, R.; Lork, E.; Azov, V. A. Tetrahedron 2009, 65, 10348-10354. doi:10.1016/j.tet.2009.10.052

44. Gaillard, F.; Levillain, E. J. Electroanal. Chem. 1995, 398, 77-87. doi:10.1016/0022-0728(95)04144-1

45. Dias, M.; Hudhomme, P.; Levillain, E.; Perrin, L.; Sahin, Y.; Sauvage, F.-X.; Wartelle, C. Electrochem. Commun. 2004, 6, 325-330. doi:10.1016/j.elecom.2004.01.010

46. Alévêque, O.; Levillain, E.; Sanguinet, L. Electrochem. Commun. 2015, 51, 108-112. doi:10.1016/j.elecom.2014.12.014

47. Torrance, J. B.; Scott, B. A.; Welber, B.; Kaufman, F. B.; Seiden, P. E. Phys. Rev. B 1979, 19, 730-741. doi:10.1103/PhysRevB.19.730

48. Andreu, R.; Garín, J.; Orduna, J. Tetrahedron 2001, 57, 7883-7892. doi:10.1016/S0040-4020(01)00766-9

49. Khodorkovsky, V.; Shapiro, L.; Krief, P.; Shames, A.; Mabon, G.; Gorgues, A.; Giffard, M. Chem. Commun. 2001, 2736-2737. doi:10.1039/B104934H

50. Rosokha, S. V.; Kochi, J. K. J. Am. Chem. Soc. 2007, 129, 828-838. doi:10.1021/ja064166x

51. Gautier, N.; Samuel, R.; Şahin, Y.; Levillain, E.; Leroy-Lhez, S.; Hudhomme, P. Org. Lett. 2004, 6, 1569-1572. doi:10.1021/ol049620l

52. Lyskawa, J.; Sallé, M.; Balandier, J.-Y.; Le Derf, F.; Levillain, E.; Allain, M.; Viel, P.; Palacin, S. Chem. Commun. 2006, 2233-2235. doi:10.1039/B518275A

53. Coskun, A.; Spruell, J. M.; Barin, G.; Fahrenbach, A. C.; Forgan, R. S.; Colvin, M. T.; Carmieli, R.; Benítez, D.; Tkatchouk, E.; Friedman, D. C.; Sarjeant, A. A.; Wasielewski, M. R.; Goddard, W. A., III; Stoddart, J. F. J. Am. Chem. Soc. 2011, 133, 4538-4547. doi:10.1021/ja110584c

54. Ziganshina, A. Y.; Ko, Y. H.; Jeon, W. S.; Kim, K. Chem. Commun. 2004, 806-807. doi:10.1039/B316651A
55. Yoshizawa, M.; Kumazawa, K.; Fujita, M. J. Am. Chem. Soc. 2005, 127, 13456-13457. doi:10.1021/ja053508g

56. Chen, P.-N.; Chiang, P.-T.; Chiu, S.-H. Chem. Commun. 2005, 1285-1287. doi:10.1039/b417823h

57. Chiang, P.-T.; Cheng, P.-N.; Lin, C.-F.; Liu, Y.-H.; Lai, C.-C.; Peng, S.-M.; Chiu, S.-H. Chem. - Eur. J. 2006, 12, 865-876. doi:10.1002/chem.200500676

58. Chiang, P.-T.; Chen, N.-C.; Lai, C.-C.; Chiu, S.-H. Chem. - Eur. J. 2008, 14, 6546-6552. doi:10.1002/chem.200800213

59. Fumanal, M.; Capdevila-Cortada, M.; Miller, J. S.; Novoa, J. J. J. Am. Chem. Soc. 2013, 135, 13814-13826. doi:10.1021/ja405352p

60. Reek, J. N. H.; Elemans, J. A. A. W.; de Gelder, R.; Beurskens, P. T.; Rowan, A. E.; Nolte, R. J. M. Tetrahedron 2003, 59, 175-185. doi:10.1016/S0040-4020(02)01480-1

61. Chen, Y.; She, N.; Meng, X.; Yin, G.; Wu, A.; Isaacs, L. Org. Lett. 2007, 9, 1899-1902. doi:10.1021/ol0704340

62. Wu, A.; Chakraborty, A.; Fettinger, J. C.; Flowers, R. A.; Isaacs, L. Angew. Chem., Int. Ed. 2002, 41, 4028-4031. doi:10.1002/1521-3773(20021104)41:21<4028::AID-ANIE4028>3.0.CO ;2-2

63. She, N.; Gao, M.; Cao, L.; Wu, A.; Isaacs, L. Org. Lett. 2009, 11, 2603-2606. doi:10.1021/ol900858d

64. Sijbesma, R. P.; Wijmenga, S. S.; Nolte, R. J. M. J. Am. Chem. Soc. 1992, 114, 9807-9813. doi:10.1021/ja00051a013

65. Macías-Ruvalcaba, N. A.; Evans, D. H. J. Electroanal. Chem. 2007, 602, 77-81. doi:10.1016/j.jelechem.2006.12.001

66. Renny, J. S.; Tomasevich, L. L.; Tallmadge, E. H.; Collum, D. B. Angew. Chem., Int. Ed. 2013, 52, 11998-12013. doi:10.1002/anie.201304157

67. Jain, A.; Rao, K. V.; Mogera, U.; Sagade, A. A.; George, S. J. Chem. - Eur. J. 2011, 17, 12355-12361. doi:10.1002/chem.201101813

68. Bivaud, S.; Balandier, J.-Y.; Chas, M.; Allain, M.; Goeb, S.; Sallé, M. J. Am. Chem. Soc. 2012, 134, 11968-11970. doi:10.1021/ja305451v

\section{License and Terms}

This is an Open Access article under the terms of the Creative Commons Attribution License (http://creativecommons.org/licenses/by/2.0), which permits unrestricted use, distribution, and reproduction in any medium, provided the original work is properly cited.

The license is subject to the Beilstein Journal of Organic Chemistry terms and conditions:

(http://www.beilstein-journals.org/bjoc)

The definitive version of this article is the electronic one which can be found at: $\underline{\text { doi: } 10.3762 / \text { bjoc. } 11.115}$ 